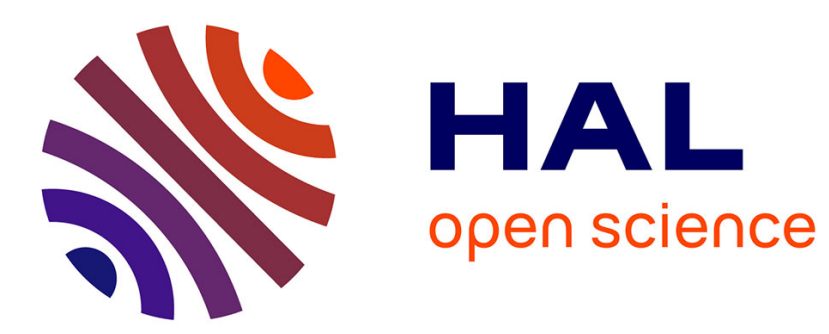

\title{
A new cosmology of risks and crises time for a radical shift in paradigm and practice
}

Patrick Lagadec

\section{To cite this version:}

Patrick Lagadec. A new cosmology of risks and crises time for a radical shift in paradigm and practice. 2008. hal-00338386

\author{
HAL Id: hal-00338386 \\ https://hal.science/hal-00338386
}

Preprint submitted on 13 Nov 2008

HAL is a multi-disciplinary open access archive for the deposit and dissemination of scientific research documents, whether they are published or not. The documents may come from teaching and research institutions in France or abroad, or from public or private research centers.
L'archive ouverte pluridisciplinaire HAL, est destinée au dépôt et à la diffusion de documents scientifiques de niveau recherche, publiés ou non, émanant des établissements d'enseignement et de recherche français ou étrangers, des laboratoires publics ou privés. 


\title{
ECOLE POLYTECHNIQUE
}

CENTRE NATIONAL DE LA RECHERCHE SCIENTIFIQUE

\section{A NEW COSMOLOGY OF RISKS AND CRISES TIME FOR A RADICAL SHIFT IN PARADIGM AND PRACTICE}

\author{
Patrick Lagadec
}

August 2008

Cahier $n^{\circ}$ 2008-08

\section{DEPARTEMENT D'ECONOMIE}

Route de Saclay

91128 PALAISEAU CEDEX

(33) 169333033

http://www.enseignement.polytechnique.fr/economie/

mailto:chantal.poujouly@polytechnique.edu 


\title{
A NEW COSMOLOGY OF RISKS AND CRISES TIME FOR A RADICAL SHIFT IN PARADIGM AND PRACTICE
}

\author{
Patrick Lagadec ${ }^{1}$
}

August 2008

Cahier $n^{\circ}$ 2008-08

Résumé: Les références tant théoriques qu'opérationnelles pour l'intelligence et la gestion des crises ont été pensées dans les années 70-80, et développées dans les années 1990. Nous avons maintenant une riche compréhension des mécanismes en jeu, et disposons de "bonnes pratiques" également validées. Pourtant, même si nous pouvons être satisfaits de ces avancées, un nouveau défi se fait jour : les crises du 21ème siècle sont structurellement différentes de celles que nous avons eues à traiter au siècle dernier. Il faut bien mesurer que le temps qui nous sépare du moment où furent pensées les crises et leur gestion est plus long encore que l'intervalle entre la fin de la Seconde Guerre mondiale et le début de la Première.

Si nous restons enfermés dans les paradigmes précédents nous "serons défaits à chaque bataille". Même s'il est particulièrement difficile de tracer de nouvelles routes dans les Terrae Incognitae, il est vital de le faire - ou au moins de s'y efforcer.

Abstract: $\quad$ Crisis management theory and practice was in the main elaborated in the late 70s and 80s and developed and implemented in the 90s. We now have a rich knowledge of crisis intelligence and best practices. But, even if we can be proud of that advance, a further challenge remains: crises in the 21st century differ-structurally - from those we had to deal with in the last century. By way of example, the disparity between now and then is equivalent to that which existed between the end of the Second World War and the beginning of the First. Thus, if we stick to former paradigms "we are bound to be defeated in every battle". Even if it is extremely difficult to forge new routes into Terrae Incognitae, it is vital to do so - or at least to try.

Mots clés : $\quad$ Crises émergentes, discontinuité, gouvernance

Key Words : Crises, emerging crises, discontinuity, decision-making

\footnotetext{
${ }^{1}$ Patrick Lagadec, Director of Research, Department of Economics, Ecole Polytechnique Paper prepared for publication after the conference "Surviving Future Disasters: Identifying critical challenges and effective strategies for transboundary disaster management", The Stephenson Disaster Management Institute (SDMI),Louisiana State University. Session 1: "Exploring future crises and disasters". 6-8 April, Baton Rouge, Louisiana, USA.
} 
"Our current system for homeland security does not provide the necessary framework to manage the challenges posed by $21^{\text {st }}$-Century catastrophic threats." The Federal Response to Hurricane Katrina - Lessons Learned The White House, 23 February 2006 [p. 52]

When Magellan decided to launch his circumnavigation of the globe, and confront unknown conditions and risks, he knew a few things: the whole cosmology of the time, based on calculations and theories of the ancient Greek and Egyptian mathematicians and astronomers, was inadequate and misleading; the "best practices", fitted for the Mediterranean sea, would certainly prove to be dangerous traps; he would have to break time-honored assumptions and, last but not least, confront the backlash of such a blasphemous disruption of accepted theory (Bergreen, 2004).

This example is a lesson for all seasons, and especially for the $21^{\text {st }}$ Century. When the world mutates (OECD, 2003), the ruling theories and best practices become outmoded, and even lethal pitfalls. The inescapable challenge is to rethink the issues, not to open additional boxes fitting the same models. The first enemy is the barriers in our minds. This is our vital challenge on the risk and crises frontline. Our cherished models, those that have been so meticulously built in the last decades, are increasingly less relevant as new horizons of risks and crises unfold (Quarantelli, Lagadec, Boin, 2006; Lagadec, P., 2006, 2007). The words of Sunzi in a crucial message resonate as a dreadful warning: "If you know neither the risks nor yourself, you are bound to be defeated in every battle" (Sunzi, 1999). "Never fight the last war [crisis]" is the name of the game (Granatt, 2004).

The goal of this paper is to set the scene for a new understanding and handling of today's hypercomplex issues. The point is not to find "the right script", "the right answer", but to sketch out the maps that could help to muddle through uncharted waters. The point is not to provide plans and tools to avoid surprise - but to prepare to be surprised (LaPorte, T. R., 2007a). We have been entirely focused on the answers, now we must shift to the questions and to invent new intelligence, attitude, and practice for a chaotic world (Lagadec, E., 2007; Cabinet Office, 2008).

\section{A Whole New Ball Game}

For decades, we have developed and consolidated a science of risk that was embedded in a strong and rewarding Cartesian philosophy. Identification, isolation, measurement, statistics, lessons of the past, best practices, ready-made effective responses in case of incident. More recently, a wide range of knowledge has been clarified in terms of crisis management: surveillance, alert, mobilization, crisis team, crisis center, crisis plans, crisis communication, mitigation and recovery, crisis drills. For serious events, a "more of the same" logic was applied: more detailed plans, more powerful tools, more coordination, and often more centralization. This vision is now outdated, to a large extent. The problem we face is that crises have evolved past the bounds of compartmentalized emergency, into the vastness of unstable and chaotic terrae incognitae.

\section{Risks and crises back to wilderness}

As L. Bernstein taught us, "The remarkable story of risk" (Bernstein, 1996) has been a victory "against the Gods" or Nature. By developing an ability to isolate the facts, recognizing 
the regularity of some events, and through an enhanced sense of apprehension and calculations, human beings and societies increasingly succeeded in controlling the flow of events. This control opened the way to great discoveries and achievements, with more and more sophisticated techniques to tame risks and vulnerabilities. Risk even became more than something to be faced. It became a set of opportunities leading to more and more triumphs. However, a series of intertwined elements of today risks compel us to revisit these paradigms.

Scale. Our whole philosophy of risk and crisis is that the event is clearly specific, isolated, independent, and above all very limited compared to the size of the systems affected. Extreme events no longer fit into that model.

The network factor. The intricacy of the vital infrastructure on which we are increasingly dependent at the national and international levels can act as a resonance chamber that will magnify a local breakdown to unprecedented proportions. On 14 August 2003, a small power fluctuation mishandled in Ohio resulted in a major power blackout effecting millions in the North eastern US and Ontario Canada. In the wake of September 11, the security of critical infrastructures came under close scrutiny (Auerswald, Brandcomb, LaPorte T. M., and Michel-Kerjan, 2006; Boin and McConnel, 2007; Boin, Lagadec, Michel-Kerjan, and Overdijk, 2003). Indeed, a commission set up by President Clinton had already touched upon this issue in 1997-98:

"Our national defense, economic prosperity, and quality of life have long depended on the essential services that underpin our society. These critical infrastructures - energy, banking and finance, transportation, vital human service, and telecommunications, must be viewed in the Information Age. The rapid proliferation and integration of telecommunication and computer systems have connected infrastructures to one another in a complex network of interdependence. This interlinkage has created a new dimension of vulnerability, which, when combined with an emerging constellation of threats, poses unprecedented national risk" (President's Commission on Critical Infrastructure Protection, 1998).

Speed. The SARS episode in 2003 showed the need to think of our vulnerabilities in the context of highly compressed time units. The combination of the virus and the jet airliner changed the rules: in just a few hours, the virus jumped from Hong Kong to Toronto: a single, symptom-free carrier was enough to shake the capital of Ontario (which lost 15,000 jobs). The 14 August 2003 power cut plunged the northeastern part of North America into darkness in less than a minute (US Canada Task Force, 2004); Europe was not far from such a massive black-out in November 2006. Today, an electronic glitch could shut down our information systems worldwide within a minute (Cukier, 2005). When we realize that it takes a good 10 days to get our systems up and running in case of a freak event (Katrina, heat waves, tsunami), this time discrepancy is a cause for concern.

Ignorance. We now often find ourselves moving from uncertainty, a dimension to which we are well accustomed, to ignorance. The issue is not totally new, but increasingly challenging, on all fronts (LaPorte, 1994). Not only do experts now find themselves at the very limits of the current state of knowledge, but their theories and plans are simply not working. An expert will in many cases have great trouble in comprehending the threat and offering a prognosis. He/she may not even know whether there is a problem at all. Such uncertainties plunge decision-making systems into disarray. This became brutally clear during the Y2K transition. It also occurred with the mad cow situation (Philips, Bridgeman and Ferguson-Smith, 2000), when stakeholders were thrust into a maelstrom of contradictory information, between concerns that there might be "millions" of victims, official 
pronouncements that the disease was harmless, and the eventual, reassuring scientific assessments in hindsight, which allowed many to regain their bearings by simply shrugging off the entire episode as much ado about nothing. In August 2003, in Europe, many officials thought it best to shrug their shoulders again over a bit of summer heat, until, over a period of 10 days, the toll mounted to a staggering 20,000 deaths in France, 20,000 in Italy, and 70000 in Europe (Lagadec, 2004). This same lack of benchmarks can be observed with all the major issues, whether they relate to climate, nanotechnology, genetic engineering or terrorism. The problem is no longer to identify what we "still" don't know, at the limit of our knowledge, but more modestly to try to discern what parcel of our available knowledge really is robust enough to answer the surge of questioning from all sides that modern crises elicit, and guide us through them when all else fails.

Hypercomplexity. Our modes of acting are configured according to "normal" benchmarks of complexity, meaning that a typical emergent event can be neatly classified within a relatively defined and stable context. Now, these benchmarks have been abruptly overwhelmed. This was the case with Hurricane Katrina on August 29, 2005. Katrina caused persistent flooding, a series of industrial disasters, critical evacuation challenges, widespread lethal pollution, the destruction of $90 \%$ of the essential utility networks (energy, communications, water etc.), unprecedented public safety concerns, concern over the possible loss of the port area (which is essential to the continent's economy), even uncertainty as to whether portions of the city could be saved. This increasingly is becoming the norm: concepts, frameworks, scientific categorizations are proving inadequate, and those who nevertheless cling to them are likely to be swept away.

The inconceivable. This is potentially the most destabilizing element of all. America had expected missiles, but it was hit with box cutters, and its own commercial planes, coming from US airports, (initially) under the helm of American pilots. We thought global epidemics were a thing of the past, and, lo and behold, the specter of a pandemic has returned. Indeed, when we look back at the flu pandemic of 1918 (Barry, 2004), we even have to acknowledge that societies of that time were probably a good deal more resilient than ours, trapped as we are by the widespread devotion to "lean process" and "just-in-time" principles that can transform a minor breakdown into a cascading domino-disaster almost instantly. What would it mean today to lose a major urban centre, a hub city?

"Category-5" media storms. As soon as an event is seen to exceed the norm and to suggest an imminent public disaster, the mass media will quickly swarm the scene, dominate coverage of the story, and thereby dictate collective representations of the emerging event. Yesterday's question was whether and how our crisis managers, the exclusive recipients of warnings, analyses, and recommendations from the experts, would pass on information to the media with sufficient transparency and understanding. The challenge for them today is how to cope when all tools of governance and "top-down" logics are promptly outflanked by these unbelievably powerful mass-media systems that are so adept at "staging" events, and even have acquired their own "situation rooms". Another front also has been opened with the Internet, blogs and vlogs. Instantly, myriads of sources are brought to bear on a situation. These in turn cause mutations that must be managed. For example, during 7/7 in London (Home Office, 2006), whoever could not instantly reach someone in London thought the nonanswering person was among the victims (Granatt and Lagadec, 2005).

In other words, the "good old" crises of the 1980s and 1990s, with their confined stage and still relatively simple rules, are undergoing mutations. 


\section{A global context prone to liquefaction}

Our fundamental approach to risk has been "the breach in the dyke" strategy. We are discovering that the "dykes" themselves are subject to in-depth "liquefaction" or destruction. Any blow can trigger extravagant domino effects, global contaminations, reactions, and mutations. Multiple and interdependent structural fault-lines increasingly appear as the decisive dimension of emerging crises.

Demography and Urbanization. The next half-century will see an increase of more than 3 billion people on earth, bringing the figure to 9.3 billion by 2050 (OECD, 2003). The increase will especially affect poor countries, coastlines and deltas - areas prone to major natural hazards. The ageing of populations will transform the risk maps in the most developed countries. The incredible growth of mega-cities will produce totally new problems and issues, with major challenges such as poverty, environment, insecurity, transportation bottlenecks, and ever less resilience.

Energy. Rising demand is sparking a price explosion in fossil fuel and in transport logistics. These pressures will develop not only because of market disruptions but because of major crises at a geostrategic level. Today, the question of "peak oil" management could bring the Western model to its knees. This is a major risk for the coming years, if not the coming months. The collapse over time of particularly vulnerable sectors could be just as destabilizing as actual physical ruptures. And "peaking" is not limited to energy (Heinberg, 2007).

Environment and Public Health. Water scarcity and pollution, soil loss through wind and water erosion, air pollution, sudden climate change can all produce major intercontinental and worldwide imbalances. To this we must add the impact of technological developments that are largely unpredictable but that will be both specific and systemic in nature such as electromagnetic radiation, bio- and nano-technology, installations reaching the end of their life cycle, and wastes of all kinds. The fields to consider are innumerable, some of which will be completely foreign to our benchmarks and our experience. The global context produces specific problems, of public health in particular, that cannot be dealt with on a local or a oneoff basis.

A "tightly-coupled" civilization. In the 1980s, we began to consider the risks of "tightly coupled" systems (Perrow, 1984, 2007). What we now have is not only a coupling of critical technical systems, but a civilization based essentially on interlinkages that are generalized, dynamic, and largely invisible, even to the operators most directly concerned. The global economy depends on this structural fragility, at least if we stick to today's rules, in particular financial rules (which have long relegated technical problems or issues of systemic sustainability to the background). The question of vulnerability, then, in fact no longer is a problem of risk affecting a sensitive point but a structural problem, one that is intimately linked to the very way our systems function.

Geostrategy, Violence. Globalization opens innumerable fault lines between people who, in the past, had been somewhat isolated from each other. All the factors discussed in this paper have become potential factors for mass destruction. "The network is the weapon", as was demonstrated (to a limited extent) in the case of postal services hit by the 2001 anthrax attacks and hoaxes (Lagadec, Michel-Kerjan and Ellis, 2006).

Economy. Our global economic system so far appears to be incapable of confronting the new challenges triggered by the subprime crisis. The indirect issue is that, traditionally, we at least had the resources (States, Insurances, public utilities, etc.) to pay for a full recovery in 
case of disasters or crisis of any kind. Now, with the economic crisis, and given the size of emerging crises, the very notion of recovery is even jeopardized.

Due to the combination of "barbarous" events and "chaotic" contexts, both open to discontinuity, and even ignorance, alarming qualifications that analysts of risks used to dismiss now no longer appear quite so remote and secondary, but major and central. It was Leibnitz's admonition in 1703: "Nature has established patterns originating in the return of events, but only for the most part" (Bernstein, 1996: 4). It was Cardano (16h Century) who in his mathematical analysis of the probabilities in dice-throwing carefully qualified his results with "... if the die is honest" (idem: 45). The crucial part of risk, and crises, increasingly lies in such blind spots, where we do not have the ready-made tools, where our best mathematical techniques no longer apply. When the map is lost, the best specific solutions vanish. The issue is not such or such point of uncertainty, but rather a global and systemic descent into this unintelligible world of the chaotic: one in which notions like "discontinuity" and the "inconceivable" become watchwords. Averages, statistical regularities, and the lessons of history are no longer pertinent points of reference. The atypical, the singular, the exceptional becomes the order of the day. And when the pace, the scope and the nature of the terrain thus depart so abruptly from accepted blueprints, our visions, our initiatives and our tools rapidly fall apart. We must rebuild them, and do so urgently. This we can only achieve if we adopt a very bold attitude, which is precisely the scientific attitude: "Be prepared to give up every preconceived notions" (Barry, 2004: 13).

\section{Facing the unknown: Inventing new cognitive and managerial maps}

"Why do we continually seem one disaster behind?" Those words of the US House of Representatives in their report on Katrina (US House of Representatives, 2006: 359) apply to any country. Crisis intelligence, crisis management, crisis preparation are globally a war behind. For all our efforts at catching up, our notions of practice of crisis management still are legacies of an obsolete set of paradigms, namely: "an accident, an answer; a larger accident, a larger answer". We will not genuinely move forward if we fail to change this mindset for one that is precisely its opposite: "no ready-made answer can be the solution to modern crises". Emerging crises call for other paradigms and other strategies. In what follows, we lay out a few landmarks to open the way.

Today, field-management, seminars and drills time and again discuss the same topics using similar expressions: "Here are the list of risks and crises, the list of plans, the rules of action; let's test our technicians' ability to apply the plans, let's study the gap between what they did and what they were supposed to do"; "if you don't have a plan, you can't act, it's better to have a bad plan than no plan", "we are here to answer questions, not to question answers", and "in crises you don't have time to think and step back". Reports which review significant emergencies all tend to make the same recommendations, which include more technical answers, more plans, more clarity in institutional and organizational fixes, more "coordination".

This quasi-universal approach will not help to prevent the vital failures: failure of imagination (National Commission, 2004), failure of initiative, failure of leadership (US House of Representatives, 2006). In order effectively to meet the challenge, we need something else, not only something more. We need to break through a whole set of embedded barriers: first of which, the cognitive barrier. 


\section{Far from Descartes: cultural and psychic breakthrough}

In the world of planning and politics, anything that is unprecedented, exceptional, non-linear is instinctively rejected. As if we were still the disciples of the naturalists of the 18th-century: "Causes which result in effects which are rare, violent and sudden must not affect us, they are not part of the ordinary process of Nature. Our causes and reasons are the effects that occur each day, movements that follow one another, effects that are continually renewed and endlessly repeated" (Buffon, 1793).

Uriel Rosenthal wrote about the fault-line, which is all the more obvious 20 years after with today emerging crises: "Scientists feel uncomfortable with phenomena that seem beyond the scope of the neatly crafted theories which have been developed on the basis of normal circumstances and events. Crises seem to be in total opposition to the very foundations of modern social science" (Rosenthal, 1989, p. 5). Peter Bernstein clarifies the most current convention: "The best decisions are based on quantification and numbers determined by the patterns of the past" (Bernstein, 1996, p. 6) - even if it does not fit with the present trend: "discontinuities, irregularities and volatility seem to be proliferating rather than diminishing" (Bernstein, 1996, p. 329). And Alvin Weinberg is definitively blunt: "Science deals with regularities in our experience. Art deals with singularities" (Weinberg, 1985).

But the most potent block is the psychological block. Crisis is profoundly destabilizing for somebody who is only prepared to manage according to solid rules, anchored on solid grounds, and selected for his/her "inside the box" excellence. Hence there can be a dramatic refusal to search for, to acknowledge, to take charge and handle extra-ordinary crises. Experience does suggest a careful reading of these lines from the psychoanalyst Nicole Fabre, writing about Descartes, who refused to consider the question vacuum, emptiness:

"His thoughts are a whole. His work also. There is no crack through which it can be attacked. There are no voids. His belief is that there is no vacuum in nature. As such his controversy with vacuum, in particular with Pascal's "quick-silver experiments" and his refusal to consider the existence of any vacuum, is so surprising in this man who referred to experiment whenever possible, to the extent that it is impossible not to see in this refusal the expression of his personality or his mode of reasoning. So much so, that I must speak of this refusal in terms of resistance. If Descartes resisted the notion of vacuum so completely, if the notion of emptiness was so inconceivable and shocking to him, it must be that to him the notion of vacuum symbolized nothingness or chaos. It represents a risk of disorder. Descartes' use of rationality to reject this concept so vigorously manifests his fear of nothingness (death?) and the fear of losing his hold on the solidity of a system which he values because it presents not the slightest chink" (Fabre, 2004: 91).

The problem is that we are collectively sons/daughters of Descartes, doing all we can as managers and even academia to stay away from, and to deny the mere existence of, anything outside normality. We must be able to cross those defensive stands, and strive to acquire the intellectual and psychological ability to move about creatively in a highly unstable and opaque world.

One might argue that some countries, France more specifically, are less immune than others from this flaw. Certainly, other cultures prove to be more suited to pragmatism, invention, the liberty to err and to cross borders. However, an overview of worldwide crisis responses demonstrates that all cultures seem inescapably drawn towards Descartes' neat and reassuring world. The three officials reports on Katrina, to take an example from the US culture (allegedly furthest removed from French rigidity), tend to promote nothing else than a philosophy, mindset and practice of "more of the same". 


\section{A new culture of signal detection}

A simple emergency requires that the specific agency responsible have the capacity to react automatically to a clear and specific warning and to feed it promptly into the normal channels. A "conventional" crisis calls for the capacity to process signals that may be weak or scattered. Emerging crises demand something else: the ability to spot the signs of phenomena that cannot be represented by any known model. In that case, the alert cannot be given automatically (as in an emergency) or largely pre-formatted (as in a known crisis), using preestablished principles.

The first obstacle is obvious: we have to capture a phenomenon not previously identified. In surveillance, we do not have a set of boxes to be filled in, nor any accurate indications of what we should or might detect. More than "weak signals", we need to look for signals that, by their nature, are virtually silent and especially elusive for the screening systems at hand.

But surveillance also encounters a second obstacle: as soon as they are detected, or even suspected, the signals we are looking for will trigger the vague sensation of a major threat to the system, which in turn triggers an irrepressible and instantaneous need to delete and avoid. It is as if signal carries within itself the ability to neutralize the receptors, and more also block activation of the alert mechanism and the transmission chains, and indeed any idea or inclination for mobilization and reaction. That is why, in their post-crisis reports, investigators have consistently declared their "consternation" upon realizing, after the fact, how many players had been deaf and blind to the event in question.

If non-conventional surveillance is to be possible, it must be entrusted basically to persons and systems with the appropriate form of intelligence. Not the "procedural intelligence", ideal for repetitive phenomena. Not even "intuitive" intelligence, when we have to work with just $20 \%$ of the necessary information. But "creative intelligence" which demands (and rewards) imagination, well beyond any given set of guidelines; and, more: people who feel comfortable and creative in a destabilized world, where the dice have not yet been rolled. Generally those people have been pushed aside by our institutions.

\section{Leadership}

"At all levels of government, we must build a leadership corps that must be populated by leaders who are prepared to exhibit innovation and take the initiative during extremely trying circumstances" (The White House, 2006: 72). But people in charge have been selected for their managerial skills: the ability to run things according to the best given practices. Emerging crises demand leaders: questions of vision and policy come to the fore. This calls for in-depth education to the unknown, specific training to confront these universes, and above all the personal capacity to be involved even when there is no ready-made, MBAcertified solution.

Leaders have to break through the conventional limits, to slip across old boundaries and invent new collective responses. When vital issues are at stake, nothing can be done without determined personal and direct involvement from the top. As Henry Kissinger put it, "The most important role of a leader is to take on his shoulder the burden of ambiguity inherent in difficult choices. That accomplished, his subordinates have criteria and can turn to implementation" (H. Kissinger, 1982: 531).

This constitutes a revolution in our culture of governance, which would rather leave it to the second ranks to anticipate risks and take charge in situations that are not yet clear. There is a tendency, in effect, to try to "protect" the leader, as long as everything is not "perfectly clear". 
Here too, one might argue that some cultures are better prepared than others. The US could be seen as more amenable to the type of leadership advocated here. An especially striking example here is that of Rudolph Giuliani, the Mayor of New York City at the time of the September 11 events. His role is easily underlined if one compares the response in New York and what occurred in New Orleans in 2005 (even if the two situations were very different in many respects). His convictions and his personal commitment on the front line of that inconceivable event were the cornerstone of the city's resilience. His advice is unambiguous: "Have beliefs and communicate them. See things for yourself. Set an example. Prepare relentlessly. Underpromise and overdeliver. Don't assume a damn thing" (Giuliani, 2002: x). Other countries could also boast their own examples of uniquelyeffective leadership.

Yet, on the whole, we can hardly deny that prevalent training models produce "managers" rather than "leaders". As Stacey underlines: "At least $90 \%$ of the content of textbooks on strategic management concentrate on the relatively easy part of the management task, namely the running of the organizational machine in as surprise-free way as possible [...]. On the contrary, the real management task involves tackling exceptions quickly and without pressure, coping with and even using unpredictability, clashing counter-cultures. The real task is about managing instability, irregularity, difference and disorder." (Stacey, 1996, p. 19-20).

This assumes that the leader himself is mentally prepared to take an approach to intelligence and action that is more creative than procedural. The problem is that our habits at times of emergency and crisis are usually just the opposite. With very little information available and even less of it verified, the leader must have the conviction and the vision to lead the community out of its initial disorientation, and to avoid the two pitfalls that are always present in extreme crises: bureaucratic inertia (where each organization waits till the crisis fits its codes and rules), and the general loss of nerve (not only within the public, but along the entire chain of command). It is only by spreading confidence that we can get through the ordeal, renew our energy, and come up with innovative plans and concrete roads to success.

Here too, conventional systems are geared the wrong way. When response efforts meet with reviews and audits will show leniency toward fiascos resulting from a strict application of the rules, but will condemn severely failure incurred through unconventional responses. In fact: it often proves even less risky to fail by the rule than to succeed through unconventional tracks.

The major challenge today is to choose and then prepare leaders so that the creative approach will prevail in the inevitable non-conventional crisis, whereas the entire organizational, administrative and institutional culture normally seeks to fall into procedural thinking (Young, 2007). In our cultures and in our selection processes, creative thinking is both punishing and punished. And this fundamental logic is not going to be turned around by devoting a few hours a year to formatted "crisis management" seminars - essentially oriented towards the teaching of the "good answers" and "best and certified practical answers".

\section{Strategic intelligence: "Rapid Reflection Forces"}

"People in government are overwhelmed by crises [...]. They do not have much time to step back and consider the big picture" (Hamilton, 2006:12). The same is true in the private sector. Yet, the importance of standing back and assessing the situation objectively is even more important in this world of discontinuity than it is in specific limited crises. The reason is clear enough: because the strategic landscape has mutated, the conventional tactics and interpretations no longer work and are even counterproductive. We must tear ourselves away from them, which demands a very active and determined effort, and then construct new frameworks for understanding and coping with reality. 
In operational terms, this means that leaders must have at hand people who are familiar with engaging chaos and who are given to thinking openly in unreadable situations. This is essential for overcoming the most severely pathological reactions to these new forms of crisis. These are: mental blocks (the constant refrain is "in a crisis, you don't have time to think"), the "bunker mentality", with everyone holing up in his own little corner; treating problems in purely technical ways and above all, rushing blindly to the most counterproductive options.

The concept and practice of Rapid Reflection Force - RFF- has been forged to try to avoid these traps. It has been implemented for example in EDF (Electricité de France, the premier French public utility in the energy sector, and the first worldwide nuclear operator). Along with the more "tactical" crisis teams, focused entirely on immediate operational responses, plans and logistics, such RRF teams promptly undertake four broad lines of questioning:

- What is the essence of the problem? The intelligence front involves a constant battle to frame, anticipate, detect and clarify the nature of the crisis, surprises, domino effects, escalation dynamics, and the general mutations that can be triggered. By definition, it is not possible to grasp all the essential issues at stake in a crisis that is new, unclear and chaotic. ${ }^{\mathrm{i}}$

- What are the major pitfalls? When the pressure of events becomes extreme, when panic spreads, when the bearings are lost, the very normal tendency is to become mired in the most counterproductive ruts. This happens with every major crisis. It is crucial, immediately, to think about the major errors to avoid. And the first error is a wrong framing of the issue.

- What is the map of actors; what networks are needed? By definition, extreme crises strike at the system in ways that are hard to anticipate, and that may differ depending on the people concerned - Katrina and heat waves (Klinenberg, 2002) being set examples. At the same time, the new issues will have to be handled with new players. New maps will be needed both for diagnosis and for action, and they will have to be adjusted or remodeled throughout the ordeal.

- What constructive initiatives can the RFF propose? The most important thing is not to pore over statistical lists or to compile all the information possible, but rather to try to discern one or a few critical initiatives that could introduce "a new ballgame", help us escape our crisis-induced mental ruts, and launch virtuous circles.

The kind of thinking that is needed here is the diametric opposite of procedural thinking. We must discriminate the essential factors, both in order to understand the crisis and to get out of it. In taking advantage of Rapid Reflection Forces, what is important is not to draw up lists of data and fill out a series of pre-formatted tables, or to get tied up in hours of teleconferencing that will be increasingly technical and focus on ever more detailed micromanagement.

Experience shows that these Rapid Reflection Forces are crucial for Executives Committees, from blowing the whistle ("there is a crisis, do wake up"), to re-checking the organizational response, and above all to delineate some creative initiative to transform the global dynamics (Béroux, Lagadec and Guilhou, 2007, 2008).

\section{Empowerment}

The years 1980-2000 were dominated by the idea of "Communication". We were told that, to manage crises, we had to give information to the public, as a democratic requirement. That in itself represented an important step forward. In fact, our tradition in times of emergency or 
catastrophe is rather that of "Command and Control". This is based on two sturdy pillars: the concentration of decision-making in a cloistered hierarchical structure, and the restriction of information held by that structure, in keeping with the military principles of the past.

It was finally admitted that the key to success in multidimensional turbulences required other approaches. It called for bringing coherence to a great number of entities, and such dynamics could not be achieved with an approach to governance that was restrictive, vertical, compartmentalized, and designed to minimize information.

We must now go much further. It is essential to provide critical information to those who will have to cope with abnormal situations on their own for some time. They must be brought decisively within the strategic loop; plans must be widely discussed with them, and their creativity and their initiative must be sought as inputs.

The problem is not to be "a bit more transparent" than before, but rather to have taken on board, in theory and in practice, the requirements of collective effort in a chaotic world. Today's environment now demands dynamic linkages, fluidity and speed, shared information, and collective confidence.

Such an avenue certainly can seem complex, even shockingly so. "When things are serious, you command, you do not consult". The contrary is true. Because public bodies are not the only one on the front line: "The 'first' responders on $9 / 11$, as in most catastrophes, were private civilians. Because 85 percent of our nation's critical infrastructure is controlled not by government but by private sector, private-sector civilians are likely to be the first responders in any future catastrophe" (National Commission, 2003: 317).

And this way is even more vital, not less, when extreme events are the challenge. This is a key lesson of 9/11: The point was not to hide information from the public to avoid panic, but to give as much information as possible to the public, to help save lives. "Firemen were impressed with the composure and total lack of panic shown by almost all civilians" (National Commission, 2004: 299). In fact, a careful analysis of the 9/11 Commission's or other key reports, from the inside (Dwyer and Flynn, 2006), show beyond doubt that one of the most vital strategy was not to "Reassure" and "Command", but to Inform and Combine. Some found a way down in the towers; the crucial issue was to obtain this information, and share it as broadly as possible. Therefore, 911 had to switch from a top-down system to a bottom-tobottom dissemination of vital pieces of information.

This was the same seminal lesson of the 1918-Pandemic: "The fear, not the disease, threatened to break the society apart" (Barry, 2006: 461). Abraham Lincoln, quoted by Berry's as the final words of his book, clarifies the ultimate issue: "Those in authority must retain the public's trust. The way to do it is to distort nothing, to put the best face on nothing, to try to manipulate no one. Lincoln said that first, and best. Leadership must make whatever horror exists concrete. Only then will people be able to break it apart” (Barry, 2006: 461).

\section{Crisis recovery: embedding the recovery issue upstream}

Until very recently, writers and experts divided a crisis into successive and clearly defined phases: the pre-crisis (the prevention and surveillance phase), the crisis itself (the acute phase of response and mitigation), and the post-crisis phase (reconstruction or recovery). This last phase came "afterward" not only in the chronological sense, but also in the setting of priorities.

The recovery dimension was deemed less important, because prevention, which was easier in a more stable and predictable world, would reduce the incidence of crises. When prevention failed, the crisis would be "managed", and any "residual" problems could be left to the last phase. 
Today, this scheme has been profoundly disrupted. The reconstruction of New Orleans after Katrina will be a decade-long affair. Crisis recovery becomes a central dimension. It must be addressed as soon as crisis management begins, and even in preparedness efforts (for example in the architecture of information and communication systems). Unless the conditions of system recovery in a major crisis are carefully considered far in advance, the obstacles may well become insurmountable during the reconstruction phase that will have to

be mounted after a severe event. But the problem is even more serious: a) the vision of a "back to normal" situation is just beside the point, there is no such thing in a chaotic context; b) reconstruction calls for a network dynamic, far from the usual bureaucratic-silo approach (Nesterenko, 2007).

\section{Preparedness for chaotic crises}

"When training, Federal officials should not shy away from exercising worst-case scenarios that "break" our homeland security system." (The White House, 2006 : 73) Our systems need to be energized in two ways. First, they must be made capable of dealing at least with relatively circumscribed crises. This already constitutes the first level of difficulty that our systems are not always able to handle. The second is much more ambitious, but goes to the core of the impending challenge. It is to launch initiatives that will unleash dynamics whereby we can learn to cope on the terrain in which we will now be engaged, that of the chaotic.

The cardinal principle is this: not to strive to foresee the unforeseeable but to train ourselves to cope with it. Not to clarify, map and plan for every single surprise, but to train to be surprised. In a simulation exercise, for example, simply asking a group to produce a scenario that is a priori "inconceivable" is itself very constructive and even liberating. Thinking out of the box is not a crime, but a vital need.

Powerful initiatives have to be launched to facilitate the confrontation with unconventional situations. Learning from difficult events is one of them. After the 2001 anthrax attacks in the United States, for example, and the thousands of false alarms in Europe, one of the author suggested to postal operators that they host an international feedback session to consider some operational initiatives for the future. The president of the French postal service, La Poste, immediately agreed to the idea, and in 2002 key representatives of about thirty operators met in Paris to share their experiences and to set up an inter-network alert and information system (Lagadec-Rosenthal, 2003; Lagadec-Michel-Kerjan, 2006). Similarly, with EDF support, international debriefing missions were conducted on the Quebec ice storm (Lagadec, 1999, 2000); on the lessons from the 2003 SARS outbreak in Toronto, relating to a potential pandemic (Lagadec-Dab, 2003); and more recently on the lessons from Katrina for big network operators (P. Lagadec, E. Lagadec, X. Guilhou, 2006). The goal is to find new visions, innovative practices, and to network internationally.

\section{Education and Research}

Until these issues are covered during initial education of prospective institutional leaders it will be very difficult to insert them on the agenda for decision-makers. Because the subject is so foreign to their frame of reference, they will be too fearful of the risks to consider and construct creative solutions. The real question, though, is this: how must we equip our future managers and citizens so that they can find new bearings, new anchor points for conviction, new tools of action in a world fraught with crisis and discontinuity? (Frémont, 2004; Taleb, 2007). This must be done, in a stable world where the disruptions to be "managed" are rare and isolated, but where discontinuity and mutation become the very matrix of evolution. Our responsibility - as ever - is to create systems of education and research that "could produce 
people capable of thinking in a new way" (Barry, $2004: 5$ ). The urgency is essential: it would be foolish to educate the next generation of leaders to managing last century emergencies.

\section{Conclusion}

“Therefore the skilful leader subdues the enemy's troops without any fighting; he captures their cities without laying siege to them; he overthrows their kingdom without lengthy operations in the field. With his forces intact he will dispute the mastery of the Empire, and thus, without losing a man, his triumph will be complete" (Sunzi, 1999:15).

It is urgent to consider the very risks of our risk analysis and crisis management culture which currently tend to become real bridgeheads of the emerging crises themselves. A striking quote attributed to Bismarck, today raises a global warning: "As long as the War College is in Paris, Germany will be fine". Fighting the crises of last century is a gigantic mistake, the mother of many collective failures. This lesson from the past is particularly pointed if the condition in Paris, or London, or Brussels or Washington, DC. still emulates the perspectives Bismarck noted in Paris. Existing courses should be reviewed with that criterion. Fundamentally, the reform advocated here in the best colleges and elite schools where "management" is taught, should aim to address this very point: Do you prepare future leaders "to apply best practices", or "to invent with others new ways into the unknown"? The method chosen is not at issue: counter-intuitively, using case studies can feed into a tendency to value the capacity to build Maginot Lines. The decisive watershed is to orient the internal dynamics of the entire preparation towards answers and ingenuity.

The essence of the watershed has to be accepted and dealt with, even if it must precipitate deep mourning for past paradigms from leaders of all executive and academia institutions. Emerging crises quit the realm of "emergency" - known problems, ready-made answers, fast response - that has been the cradle of crisis research and practice. Emerging crises go beyond the realm of "emergency" known problems, ready-made answers and fast response that has been the cradle of crisis research and practice. Crisis now has to split from this "emergency" rut. Crisis is becoming the core dynamics, the biological texture, the very identity of an unknown world, whose laws combine extreme, ignorance, discontinuity and chaotic turbulence. The name of the game is not the fixed, reassuring and successful answers, but the intellectual, psychic and leadership capacity to open the questions and draw new maps to sail such unknown territories, with their Capes Horn, rogue waves, and fuzzy environments (LaPorte, 2007b)

On all fronts, intellectual, managerial, governance, conviction, we must now acquire the skills and the openness to address the new vulnerability issues. We must venture resolutely to these new frontiers, in order to understand them and to improve our skills, in terms of vision, strategies and tools - in order to better master our destiny in these particularly turbulent times.

Some could still argue that those "out-of-the-box problems" are not "scientific problems", or "governance issues". We do know, after Thomas Kuhn (Kuhn, 1962) that science is not particularly interested at changing paradigms, and much prefers just to improve understanding and know-how in the dominant paradigm. We will have to understand that the global conditions do not leave us such a luxury. When issues are that vital, science cannot hide in the its well known regions. This represents a real challenge, and a revolution, but there is no choice. Identically, some could argue that institutions are not fitted for stormy environments: they even tend to prefer the pursuit of policy contrary to self-interest than inventing some new ways (Tuchman, 1984). Such a line of defense could be disastrous. If institutions cave in "normal contexts" they will rapidly restrain their function to a kind of museum activity. 
The specifics of the challenge are new; but the fundamentals are not. Abraham Lincoln's words resonate as a solid blueprint for today: "The dogmas of the quiet past are inadequate for the stormy present. The occasion is piled high with uncertainty, and we must rise to the occasion. As our case is new, so we must think anew, and act anew" (Lincoln, 1861). The 21 ${ }^{\text {st }}$ Century appears much more turbulent than ever, due to the globalization of every butterfly movement, and the mutation of deep-rooted global equilibriums. Contemporary Magellans will need a great deal of intelligence, courage and determination. But failure is not an option.

\section{Acknowledgements}

The author would like to thank Dr James Young, O. Ont., M.D, until recently Special Advisor to the Deputy Minister, Public Safety Canada, Todd R. LaPorte, Professor of Political Science at the Univ. of California, Berkeley, Erwan Lagadec, Fellow at the School of Advanced International Studies, Johns Hopkins University, who have given me fruitful comments on the draft of this contribution.

\section{Notes}

1 Admiral Thad Allen's experience illustrates this. When he arrived in Louisiana some 10 days after the landing of Katrina, the essential characterization of the problem had not been done, people were dealing with a "common Hurricane", but it was not. It was "a weapon of mass destruction without criminal dimension" (Thad Allen, 2008). Margaret Hermann, analyzing 9/11, underlines too the crucial importance of the very initial framing of the problem at the outset of a crisis: "Within an hour Tony Blair was on TV and said: 'This is a crime against civilization'. Later he talked about it being a matter for the police, legal system, and rule of law. Justice was the focus of his framing. A week later, I came back to the US and 9/11 had been framed as an attack against America. Which means it is military, it's war, and it's nationalism. Ladies and Gentlemen, it's the same event defined and framed in a very different ways. The options you are being given are very limited by this frame and one of the difficulties between Europe and the USA in dealing with terrorism has been based in that framing of 9/11" (Hermann, 2008).

\section{References}

Allen, Thaad, Admiral (2008), "Hurricane Katrina: framing the issue - A weapon of mass destruction without criminal dimension", vido-taped communication to Hans De Smet, Department of Economics, Management \& Leadership, Royal Military Academy, Brussels.

Auerswald, Philip, Lewis M. Brancomb, Todd M. LaPorte and Erwann Michel-Kerjan (eds) (2006): Seeds of Disaster, Roots of Response. How Private Action Can Reduce Public Vulnerability, Cambridge University Press.

Barry, John, M. (2004), The Great Influenza - The Epic Story of the Deadliest Plague in History, Penguin Books, New York.

Bergreen Lawrence (2004), Over the Edge of the World -Magellan's Terrifying Circumnavigation of the Globe, Harper Perennial, New York.

Bernstein, Peter L. (1996), Against the Gods, The Remarkable Story of Risk, John Wiley \& Sons, New York. 
Béroux, Pierre, Xavier Guilhou, Patrick Lagadec (2008): "Rapid Reflection Forces put to the reality test", Crisis Response, Vol 4, Issue 2, March 2008, pp. 38-40.

Béroux, Pierre, Xavier Guilhou, Patrick Lagadec (2007): "Implementing Rapid Reflection Forces", Crisis Response, vol. 3, issue 2, March 2007, pp. 36-37.

Boin, R. Arjen, Allan McConnel (2007): Preparing for Critical Infrastructure Breakdowns: The Limits of Crisis Management and the Need for Resilience", Journal of Contingencies and Crisis Management, Volume 15, Number 1, pp. 50-59.

Buffon (1749), Théorie de la Terre, quoted in Jean Delumeau and Yves Lequin : Les Malheurs des temps - Histoire des fléaux et des calamités en France ; Mentalités : vécu et représentations, Larousse, 1987, p. 397.

Cabinet Office (2008): The National Security Strategy of the United Kingdom - Security in an interdependent world, HMSO.

Cukier, Kenneth (2005), Critical Information Infrastructure Protection, Ensuring (And Insuring?) Critical Information Infrastructure Protection, A Report of the 2005 Rueschlikon Conference on Information Policy, The Rueschlikon Conferences, in Cooperation with Swiss Re Center for Global Dialogue.

Dwyer, Jim and Kevin Flynn (2006), 102 Minutes - The Untold Story of the Fight to Survive Inside the Twin Towers, Times Books Henry Holt and Company, LLC, New York.

Fabre, Nicole (2004), L'inconscient de Descartes, Bayard, Paris, p. 91.

Frémont, Christian (2004):"Governance and Responsability in a chaotic world", personal video-taped communication.

Granatt, Mike (2004), "Complexity Crises - Never Fight the Last War", personal video-taped communication.

Granatt, Mike and Patrick Lagadec (2005): "Ethics for media commentators", Crisis Response Journal, Vol. 2, Issue 1, December 2005, p. 36-37.

Hamilton (2006), "Prologue", in Thomas H. Kean and Lee H. Hamilton (2006), Without Precedent, The Inside Story of the 9/11 Commission, Alfred A. Knoff, New York.

Hermann, Margaret (2008), Presentation, LSU conference on future disaster, Baton Rouge, April 2008.

Heinberg, Richard (2007), Peak Everything, Waking up to the Century of Decline in Earth's Resources, Clairview.

Home Office (2006), “Addressing Lessons from the Emergency Response to the 7 July 2005 London Bombings - What we learned and what we are doing about it", 22 September 2006". 
Kissinger, Henry (1982), Years of Upheaval, Boston Little, Brown \& Company.

Klinenberg, Eric (2002), Heat Wave, A Social Autopsy of Disaster in Chicago, The University of Chicago Press, Chicago and London.

Kuhn, Tomas (1962), The Structure of Scientific Revolution, University of Chicago Press.

Lagadec, Erwan (2007): Unconventional Crises, Unconventional Responses Reforming Leadership in the Age of Catastrophic Crises and Hypercomplexity, Center for Transatlantic Relations, The Paul Nitze School of Advanced International Studies, The Johns Hopkins University, Washington DC.

Lagadec, Patrick (2007), "Over the edge of the world", Crisis Response Journal, vol. 3, issue 4, September 2007, pages 48-49.

Lagadec, Patrick (2006), "Crisis Management in the Twenty-First Century - "Unthinkable" Events in "Unthinkable" Contexts", in Havidan Rodriguez, Enrico L. Quarantelli, and Russel R. Dynes: Handbook of Disaster Research, Springer, September 2006. (Chapter 30, pp. 489-507).

Lagadec, Patrick, Erwann O. Michel-Kerjan, and Ryan N. Ellis (2006), "Disaster via Airmail - The Launching of a Global Reaction Capacity After the 2001 Anthrax Attacks", Innovations, The MIT Press, Technology/Governance/ Globalization, Philip E. Auerswald and Iqbal Z. Quadir, Editors, Summer 2006, p. 99-117.

Lagadec, Patrick (2004), "Understanding the French 2003 Heat Wave Experience: Beyond the heat, a Multi-Layered Challenge". Journal of Contingencies and Crisis Management, Vol. 12, pp. 160-169.

LaPorte, Todd R. (2007a), "Critical Infrastructure in the Face of a Predatory Future: Preparing for Untoward Surprise”, Journal of Contingencies and Crisis Management, Vol. 15, $\mathrm{n}^{\circ} 1$, March 2007, p. 60-64.

LaPorte, Todd R (2007b), "Anticipating Rude Surprises: Reflections on "Crisis Management" Without End," ch 2. pp. 27-46 L. Jones, ed., Communicable Crises: Prevention, Management and Resolution in the Global Arena. Elsivier, 2007.

http://www.polisci.berkeley.edu/faculty/bio/emeriti/LaPorte,T/RudeSurprisesIPMRConf05.pdf

LaPorte, Todd R. (1994), "A State of the Field: Increasing Relative Ignorance," Journal of Public Administration Research and Theory, 4, 1, 5-15.

Lincoln, Abraham (1861), State of the Union Address, December 3.

National Commission on Terrorist Attacks upon the United States (2004): "The 9/11 Commission Report », Final Report, Authorized Edition, Norton

Nesterenko (2007): “The Day After - Priorities in reconsctruction", Crisis Response Journal, Volume 3 Issue 4

OECD (2003), Emerging Risks in the 21st Century, An Agenda for Action, Paris. 
Perrow, Charles (1984), Normal Accidents, Living with high risk technologies, Pinceton, NJ, Princeton University Press.

Perrow, Charles (2007), "The Next Catastrophe - Reducing Our Vulnerabilities to Natural, Industrial, and Terrorist Disasters”, Princeton University Press.

President's Commission on Critical Infrastructure Protection, Critical Foundations, Protecting America's Infrastructures, Washington D.C., 1998, p. ix.

Philips of Worth Matravers (Lord), June Bridgeman, Malcom Ferguson-Smith, (2000): The BSE Inquiry, House of Commons, London, HMSO.

Quarantelli, Enrico L., Patrick Lagadec and Arjen Boin (2006): "A Heuristic Approach to Future Disasters and Crises: New, Old and In-Between Types", in R. Dynes, H. Quarantelli, and H. Rodriguez, Handbook of Disaster Research, Springer, September 2006. (Chapter 2, pp. 16-41)

Rosenthal, Michael T. Charles, Paul 't Hart (Ed.) (1989): Coping with crises. The Management of Disasters, Riots and Terrorism, Charles C. Thomas Publisher, Springfield, Illinois, 1989.

Stacey, Ralf (1996): Strategic Management \& Organizational Dynamics, Pitman, London.

Sunzi (1999), The Art of War, Library of Chinese Classics, Foreign Languages Press, Beijing, p. 23.

Taleb, Nassim Nicholas (2007), The Black Swan - The Impact of the Highly Improbable, Allen Lane, Penguin Books, London.

The White House (2006), The Federal Response to Hurricane Katrina-Lessons Learned.

Tuchman, Barbara W. (1984), The March of Folly, From Troy to Vietnam, Ballantine Books, New York.

U.S. - Canada Power System Outage Task Force (2004), "Final Report on the August 14, 2003 Blackout in the United States and Canada: Causes and Recommendations", April 2004.

U.S. House of Representatives (2006), A Failure of Initiative, Final Report of the Select Bipartisan Committee to Investigate the Preparation for and sponse to Hurricane Katrina, US Government Printing Office.

Weinberg, Alvin (1985), "Science and its Limits. The Regulator's Dilemma". Issues in Science and Technology 2 (1), 1985, pp. 59-72. Quoted in Kandra, J \& Wachtendorf, T. "Elements of Resilience After the World Trade Center Disaster: Reconstituting New York City’s Emergency Operations Center”, Disaster, 27 (1), 2003, pp. 37-53.

Young, James (2007), "Leadership in the age of unconventional crises and chaotic environment", personal video-taped communication. 
